九州大学学術情報リポジトリ

Kyushu University Institutional Repository

The aryl hydrocarbon receptor is indispensable for dioxin-induced defects in sexuallydimorphic behaviors due to the reduction in fetal steroidogenesis of the pituitary-gonadal axis in rats

Hattori, Yukiko

Graduate School of Pharmaceutical Sciences, Kyushu University | Research Fellow of Japan Society for the Promotion of Science

Takeda, Tomok i

Graduate School of Pharmaceutical Sciences, Kyushu University

Nakamura, Arisa

Graduate School of Pharmaceutical Sciences, Kyushu University

Nishida, Kyoko

Graduate School of Pharmaceutical Sciences, Kyushu University

他

http://hdl. handle. net/2324/1931496

出版情報: Biochemical pharmacology. 154，pp.213-221，2018-05-16 バージョン：

権利関係 : 
Biochemical Pharmacology

Original Article (MS. No. BCP-D-18-00278)

\section{The aryl hydrocarbon receptor is indispensable for dioxin-induced defects in sexually-dimorphic behaviors due to the reduction in fetal steroidogenesis of the pituitary-gonadal axis in rats}

Yukiko Hattori* ${ }^{* 1,2}$, Tomoki Takeda ${ }^{1}$, Arisa Nakamura ${ }^{1}$, Kyoko Nishida $^{1}$, Yuko Shioji ${ }^{1}$, Haruki Fukumitsu ${ }^{1}$, the late Hideyuki Yamada ${ }^{1}$ and Yuji Ishii ${ }^{1}$

${ }^{1,}$ Graduate School of Pharmaceutical Sciences, Kyushu University, Fukuoka, Japan

${ }^{2,}$ Research Fellow of Japan Society for the Promotion of Science, Tokyo, Japan

*The authors equally contributed to this work.

\section{Corresponding Author:}

Y. Ishii, Graduate School of Pharmaceutical Sciences, Kyushu University, 3-1-1 Maidashi, Higashi-ku, Fukuoka 812-8582, Japan, Tel.: +81-92-642-6586; Fax: +81-92-642-6588; E-mail: ishii@phar.kyushu-u.ac.jp

Categories: Toxicology 


\section{Abstract}

Many forms of the toxic effects produced by dioxins and related chemicals take place following activation of the aryl hydrocarbon receptor (AHR). Our previous studies have demonstrated that treating pregnant rats with 2,3,7,8-tetrachlorodibenzo- $p$-dioxin (TCDD), a highly toxic dioxin, attenuates the pituitary expression of gonadotropins to reduce testicular steroidogenesis during the fetal stage, resulting in the impairment of sexually-dimorphic behaviors after the offspring reach maturity. To investigate the contribution of AHR to these disorders, we examined the effects of TCDD on AHR-knockout (AHR-KO) Wistar rats. When pregnant AHR-heterozygous rats were given an oral dose of $1 \mu \mathrm{g} / \mathrm{kg}$ TCDD at gestational day (GD) 15, TCDD reduced the expression of pituitary gonadotropins and testicular steroidogenic proteins in male wild-type fetuses at GD20 without affecting body weight, sex ratio and litter size. However, the same defect did not occur in AHR-KO fetuses. Further, fetal exposure to TCDD impaired the activity of masculine sexual behavior after reaching adulthood only in the wild-type offspring. Also, in female offspring, not only the fetal gonadotropins production but also sexual dimorphism, such as saccharin preference, after growing up were suppressed by TCDD only in the wild-type. Interestingly, in the absence of TCDD, deleting AHR reduced masculine sexual behavior, as well as fetal steroidogenesis of the pituitary-gonadal axis. These results provide novel evidence that 1) AHR is required for TCDD-produced defects in sexually-dimorphic behaviors of the offspring, and 2) AHR signaling plays a role in gonadotropin synthesis during the developmental stage to acquire sexual dimorphism after reaching adulthood. 
Keywords 2,3,7,8-Tetrachlorodibenzo- $p$-dioxin (TCDD), Aryl hydrocarbon receptor knockout (AHR-KO) rat, sexually-dimorphic behavior, fetus, gonadotropin, pituitary-gonadal axis 


\section{Introduction}

Dioxins are a class of environmental pollutants, and their harmful effects on health and development of humans, wildlife and their future generations continue to be of much concern. One of the reasons why dioxins are severe is their persistent nature due to the high lipophilicity and resistance to metabolic transformation. For example, the biological half-life of 2,3,7,8-tetrachlorodibenzo- $p$-dioxin (TCDD), the most toxic congener of dioxins, ranges from 2 to 4 weeks in most rodents [1], and that in adult humans is over 5 years [2]. It is known that TCDD produces a variety of toxic effects such as wasting syndrome, hepatotoxicity, tumorigenicity and immunotoxicity [3], which are triggered following activation of the aryl hydrocarbon receptor $(\mathrm{AHR})[4,5]$. AHR is a ligand-activated transcription factor which belongs to the basic helix-loop-helix/Per-Arnt-Sim (bHLH/PAS) family. In the absence of ligands, AHR is present as a complex with heat shock protein 90, p23 and AHR-interacting protein in the cytoplasm [6]. Upon binding of the ligands including TCDD, AHR dissociated from the complex migrates to the nucleus, and dimerizes with another bHLH/PAS protein, AHR nuclear translocator. This heterodimer binds to the xenobiotic responsive element (XRE) in promoter regions of genes, including cytochrome P450 (CYP) 1A1 and other xenobiotic-metabolizing enzymes, to alter their expressions $[7,8]$.

More importantly, maternal exposure to dioxin causes the impairment of reproduction and development in the offspring [9]. For example, in utero and lactational exposure to TCDD results in the offspring suffering from reduced body weight and length [10] and defects in sexually-dimorphic behaviors, such as sexual behavior and saccharin preference [11-13]. Several human studies have also suggested that maternal 
levels of dioxins and other AHR agonists are negatively linked to development, including body weight and sexual dimorphism and maturation of children [14-17]. In rats, although less than $0.1 \%$ of the TCDD dose exposed to pregnant dams is transferred to fetuses through the placental barrier $[18,19]$, it causes developmental disorders in the offspring despite having little effects on dams exposed to TCDD. In addition, these effects continue even after the offspring reach maturity. For these reasons, the effects on later generations are extremely serious, and it is important to clarify the molecular mechanisms, including the contribution of AHR to these disorders.

A series of our previous studies have demonstrated that treating pregnant Wistar rats with TCDD at gestational day (GD) 15 reduces the pituitary production of gonadotropins [luteinizing hormone ( $\mathrm{LH})$ and follicle-stimulating hormone (FSH)] only during the fetal and neonatal period to attenuate the expression of steroidogenic proteins such as steroidogenic acute-regulatory protein (StAR) and CYP17 in their gonads [20, 21]. Also, the reduced expression of $\mathrm{LH}$ is due to deacetylation of histones wrapped around its promoter region through the induction of histone deacetylase (HDAC) mRNAs in the fetal pituitary [21]. In addition, direct supplementation of equine chorionic gonadotropin, an LH-mimicking hormone, in fetuses restored the TCDD-induced impairment of sexual behaviors after reaching maturity as well as testicular steroidogenesis during the fetal stage $[22,23]$. These pieces of evidence strongly suggest that TCDD initially targets epigenetic regulation to attenuate the synthesis of pituitary LH during the fetal period, and this outcome leads to the imprinting of defects in sexual behaviors after reaching adulthood. Based on the above evidence, the present study was designed to examine the role of AHR in TCDD-induced 
defects in fetal steroidogenesis of the pituitary-gonadal axis and its outcomes on sexual maturation, using AHR-knockout $(\mathrm{KO})$ rats generated by transcriptional activator-like effector nuclease (TALEN) technology [24]. 


\section{Materials and methods}

\subsection{Materials}

TCDD was purchased from AccuStandard, Inc. (New Haven, CT). Anti-rabbit StAR polyclonal antibody and anti- $\beta$-actin mouse monoclonal antibody were obtained from Santa Cruz Biotechnology Inc. (Dallas, TX) and BioVision Inc. (Mountain View, CA), respectively. The other reagents were of the highest grade commercially available.

\subsection{Animals and Treatments}

All experiments were approved by the Institutional Animal Care and Experiment Committee of Kyushu University. AHR-KO rats were produced using TALEN technology as described previously [24]. AHR heterozygous (AHR-Het) female and male rats were given sterilized tap water and standard chow (CE-2; CLEA Japan, Tokyo, Japan) ad libitum. They were kept in a room maintained at $22 \pm 5^{\circ} \mathrm{C}$ and $50 \pm 15 \%$ relative humidity under a $24 \mathrm{~h}$ light/dark cycle (light period, 7:00 AM-7:00 PM). Female rats were paired overnight with male rats. The next morning, sperm in the vaginal smears was checked by microscopy $(\times 400)$ to confirm pregnancy. The day when sperm was detected was designated as GD0 of pregnancy, and the pregnant rats were housed alone before the experiment was started. Considering the effect of the genetic background in dams, we obtained all offspring by crossing AHR-Het female rats onto AHR-Het males, and selected only the offspring of dams in which three different genotypes were included in one littermate (Fig. 1A). Pregnant AHR-Het rats at GD15 were given an oral dose of TCDD ( $1 \mu \mathrm{g} / \mathrm{kg} / 2 \mathrm{ml}$ corn oil), and the tissues and blood 
were collected from their wild-type, AHR-Het and AHR-KO fetuses at GD20. Our previous study confirmed that maternal exposure to TCDD reduces steroidogenesis of the fetal pituitary-gonadal axis in a dose-dependent manner, and its effective dose 50 is around $0.4 \mu \mathrm{g} / \mathrm{kg}$ [25]. Referring to the above evidence, this study used the maternal dose of $1 \mu \mathrm{g} / \mathrm{kg}$ TCDD which was enough to impair not only steroidogenesis during the fetal stage but also sexual behavior of the offspring after reaching maturity. Control dams were treated with corn oil alone. For the assessment of sexual behaviors and saccharin preference, fetuses were allowed to be born and develop before the experiments. Each genotype of litters was determined according to the method reported previously [24] (Fig.1B), using the cDNA of the fetal pituitary or genomic DNA (gDNA) extracted from the ear of postnatal offspring.

\subsection{Reverse transcription-polymerase chain reaction (RT-PCR)}

The fetal pituitary and testis at GD20 were collected individually. The expression of mRNAs was quantified by real-time RT-PCR according to the method described previously [26]. Briefly, the total RNA was extracted from each tissue using RNeasy kits (QIAGEN GmbH, Hilden Germany). The cDNAs were synthesized by PrimeScript ${ }^{\circledR}$ RT reagent Kit with gDNA Eraser (Perfect Real Time, TaKaRa-bio, Shiga, Japan). The RNA (150 ng) obtained was treated with gDNA Eraser to digest contaminating genomic DNA, and then reverse-transcribed to synthesize cDNAs. The cDNA of target mRNA was amplified with Fast SYBR Green Master Mix (Thermo-Fisher Scientific, Inc., Waltham, MA), using a StepOnePlus Real-time PCR system (Thermo-Fisher Scientific). The primer designs are shown in Table 1. The PCR 
conditions were as follows: $95^{\circ} \mathrm{C}, 20 \mathrm{~s}-40$ cycles $\left(95^{\circ} \mathrm{C}, 3 \mathrm{~s}-60^{\circ} \mathrm{C}, 30 \mathrm{~s}\right)$. The amplification efficiency of each primer set $(\%$, mean \pm SEM of three analyses) was as follows: $\beta$-actin, $107 \pm 6 ; \mathrm{LH} \beta, 96 \pm 10 ; \mathrm{FSH} \beta, 93 \pm 4 ; \operatorname{StAR}, 100 \pm 11$; gonadotropin-releasing hormone receptor (GnRHR), $94 \pm 3$; GnRH, $108 \pm 11$; and gonadotropin inhibitory hormone $(\mathrm{GnIH}), 101 \pm 12$ [27, 28]. Each relative expression of mRNAs was determined using the $2^{-{ }_{\alpha \Delta} \mathrm{CT}}$ method. The amount of quantified target mRNAs was normalized by $\beta$-actin mRNA, and shown as a ratio to the wild-type control.

\subsection{Enzyme-linked immunosorbent assay}

The serum LH and testosterone were determined using commercial kits obtained from the following sources: LH (Endocrine Technologies, Inc., Newark, CA) and testosterone (Cayman Chemical, Ann Arbor, MI). In the assays for LH and testosterone, fetal sera were diluted two- and twenty five-fold, respectively, with the assay buffer contained in the kit. The serum of 13 week-old animals was diluted two-fold before the assay.

\subsection{Immunoblotting}

The protein level of testicular StAR and $\beta$-actin was analyzed by immunoblotting according to the method described earlier with minor modifications [22]. In brief, fetal testis was homogenized in $30 \mu \mathrm{l}$ homogenizing buffer [ $5 \mathrm{mM}$ potassium phosphate buffer ( $\mathrm{pH}$ 7.4) containing $0.25 \mathrm{M}$ sucrose, $0.5 \mathrm{mM}$ EDTA, $1 \mathrm{mM}$ dithiothreitol, $20 \%$ glycerol and protease inhibitor cocktail (Roche Diagnostics, Basel Schweiz, 
Switzerland)]. Those were then centrifuged at $1,000 \mathrm{x} \mathrm{g}$ for $10 \mathrm{~min}$, and the supernatants were centrifuged at $9,000 \mathrm{x} \mathrm{g}$ for $20 \mathrm{~min}$. The pellets obtained were washed once with $0.2 \mathrm{ml}$ homogenizing buffer, and suspended in PBS containing $5 \mathrm{mM}$ EDTA and 1\% Nonidet P-40 to obtain mitochondrial fractions (10 $\mu$ per testis). The mitochondrial sample was electrophoresed in $10 \%$ sodium dodecyl sulfate-polyacrylamide gel, and detection of proteins was carried out using rabbit anti-StAR (1:1,000; Santa Cruz Biotechnology) and mouse anti- $\beta$-actin (1:500; BioVision) IgGs as the primary antibodies. Alkaline phosphatase-labeled goat anti-rabbit IgG (1:1,000; Thermo-Fisher Scientific) and goat anti-mouse IgG (1:1,000; Sigma-Aldrich, St. Louis, MO) were used as the secondary antibody for detection of StAR and $\beta$-actin, respectively. The amount of proteins used for electrophoresis was 5 $\mu \mathrm{g}$ for both StAR and $\beta$-actin.

\subsection{Sexual Behaviors and Saccharin Preference}

The sexual behaviors of male rats and saccharin preference of female rats were examined according to the method described elsewhere [22]. Male rats at 10 and 11 weeks of age were paired with hormone-primed female rats for $30 \mathrm{~min}$, and the number and latency of intromission behaviors, the action of mounting with inserting the penis into the female vagina, were determined. Saccharin preference in female rats was evaluated over two consecutive days of 9 week-old animals. The percentage ingested volume of $0.01 \%$ saccharin solution to total water consumption was measured and averaged every $24 \mathrm{~h}$. 


\subsection{Open-field test}

The locomotor activity and anxiety-related behaviors of male rats at 5 week-old were examined by the open field test. The test module consists of a $60 \mathrm{~cm} \times 60 \mathrm{~cm}$ plastic square surrounded by walls of $45 \mathrm{~cm}$ height. At the beginning of the test period, the rat tested was placed in the center of the module, and was allowed to move freely for $5 \mathrm{~min}$. The behavior of rats was monitored and recorded using a video tracking software Ethovision XT9 (Noldus Information Technologies, Wageningen, The Netherlands). The total distance was calculated to assess the locomotor activity. In addition, the $36 \mathrm{~cm}$ square at the center of the field was set as the center area, and time spent and the number of entries in the center area were analyzed as the indices of anxiety-related behaviors. Because rats which are resistant to anxiety tend to enter and stay in the center area, the time spent and the number of entries in the center area is altered by the status of anxiety.

\subsection{Statistical Analysis}

The statistical differences from each control group of wild-type, AHR-Het or AHR-KO were determined by one-way analysis of variance with Dunnett's multiple comparison test, using Excel Statistics 2010 software (Social Survey Research Information Co. Ltd., Tokyo, Japan). The statistical significance was set at $p<0.05$. 


\section{Results}

\subsection{The effect of TCDD and AHR on the growth of offspring}

We firstly examined the effect of maternal exposure to TCDD and AHR ablation on the growth of offspring. Pregnant AHR-Het rats at GD15 were orally treated with TCDD, and the pituitary expression of mRNAs coding for AHR and CYP1A1, an AHR-responsive gene, were analyzed in male wild-type, AHR-Het and AHR-KO fetuses at GD20. As expected, the TCDD-produced induction of the expression of CYP1A1 mRNA as well as the constitutive level of AHR mRNA was hardly detectable in AHR-KO fetuses (Fig. 1C). Neither maternal treatment with TCDD nor AHR deletion altered the litter size, sex ratio and percentage of AHR-KO offspring at GD20 and postnatal day (PND) 21 (Table 2). Also, the lack of AHR did not change the body weight of offspring at GD20 and PND21. However, TCDD appeared to delay the growth of offspring via activation of their own AHR, because the TCDD-induced attenuation in body weight did not occur in AHR-KO offspring at PND21 (Table 2).

\subsection{Role of AHR in the dioxin-produced attenuation in fetal steroidogenesis of the pituitary-gonadal axis}

To investigate the contribution of AHR activation to the TCDD-induced damage to the fetal production of pituitary gonadotropins and testicular steroidogenesis, mRNAs coding for pituitary gonadotropins and testicular StAR and CYP17 were analyzed in 
GD20 male fetuses whose mothers were exposed to TCDD at GD15. In accordance with our previous studies using wild-type dams [20, 22], TCDD significantly reduced the expression of LH $\beta$ and FSH $\beta$ mRNAs in male wild-type fetuses. However, the same effect did not occur in male AHR-KO and AHR-Het fetuses (Fig. 2A). Concomitant changes were observed in the circulating level of LH (Fig. 2B). In support of evidence that TCDD targets the induction of HDACs to produce the lowered synthesis of LH $\beta$ [21], the expression of HDAC5 and HDAC7 mRNAs was induced by maternal exposure to TCDD only in wild-type fetuses (Fig. 3A). In addition, although there were no effects of TCDD on the mRNA expression of hypothalamic regulators for the pituitary synthesis of gonadotropins, such as GnRH, GnIH and kiss1 (Fig. 3B), TCDD reduced the pituitary expression of GnRHR mRNA in an AHR dependent fashion (Fig. 3A). Such AHR-dependent effects were also observed in terms of testicular steroidogenesis. That is, TCDD attenuated the testicular expression of mRNAs coding for StAR and CYP17 (Fig. 4A), the testicular StAR protein level (Fig. 4B), and the serum concentration of testosterone (Fig. 4C) only in male wild-type fetuses. Alternatively, these analyses found that the control levels of testosterone and pituitary gonadotropins were higher in wild-type than AHR-KO fetuses (Figs. 2 and 4). These results indicate that maternal exposure to TCDD disturbs fetal steroidogenesis of the pituitary-gonadal axis due to activation of AHR, and this receptor possibly plays an important role in regulation of the constitutive expression of pituitary gonadotropins and testicular steroidogenesis during the fetal stage.

\subsection{Effect of maternal exposure to TCDD on the expression of gonadotropins and}




\section{sexual behavior in male wild-type and AHR-KO offspring after reaching adulthood}

We then examined the effect of maternal exposure to TCDD on sexual maturation in male wild-type and AHR-KO offspring after they reached adulthood. In male offspring at PND49, the body weight and anogenital distance (AGD), an index of sexual maturation, was not significantly affected by fetal exposure to TCDD (Table 3). The TCDD-produced reduction both in the pituitary expression of gonadotropin mRNAs and in the serum level of LH had already disappeared in 13 week-old offspring (Fig. 5A and B), suggesting that the defect in sex-steroid biosynthesis in the TCDD-exposed offspring returns to normal after reaching adulthood. However, the frequency and latency of intromission behaviors, representative masculine sexual behaviors, in male wild-type offspring after reaching maturity were, respectively, markedly reduced and delayed by maternal exposure to TCDD (Fig. 5C), while TCDD failed to cause any significant change in AHR-KO offspring (Fig. 5C). The comparison of the data between AHR-KO and wild-type control offspring also demonstrated that the absence of AHR causes suppression of masculine sexual behavior without changing the body weight, AGD and expression of gonadotropins (Fig. 5 and Table 3). In contrast, none of change was observed in terms of locomotor activity (Fig. 6A) and anxiety-related behavior (Fig. 6B) between AHR-KO and wild-type control offspring. These results strongly support the mechanism that TCDD imprints defects in sexual behaviors by triggering AHR-dependent attenuation in pituitary gonadotropins during the fetal period. Furthermore, it is suggested that AHR itself contributes to the acquisition of 
sex-specific behaviors after reaching adulthood.

\subsection{Role of AHR in dioxin-induced impairment in the sexual dimorphism of female offspring}

For a better understanding of the relationship between AHR and sexual maturation, it is helpful to clarify the contribution of AHR activation or ablation to the sexual maturation of females. Then, we investigated whether the TCDD-produced attenuation in gonadotropin levels at the fetal stage and saccharin preference, one of the female-specific traits, at adulthood occur in female AHR-KO offspring. Just like male offspring, an AHR-dependent reduction in the pituitary expression of gonadotropins in female fetuses was observed following maternal treatment with TCDD (Fig. 7A). Maternal exposure to TCDD reduced the body weight and shortened the urethrovaginal distance (UVD), an index of female sexual maturation, only in wild-type offspring at PND49, whereas the AGD were insensitive to this treatment (Table 3). In accordance with a previous study [13], saccharin preference was reduced by maternal exposure to TCDD in female wild-type offspring at adulthood (Fig. 7B). However, female AHR-KO rats were resistant to such treatment (Fig. 7B). Additionally, deleting AHR attenuated or tended to attenuate not only the pituitary expression of gonadotropins at the fetal stage but also UVD at adulthood (Fig. 7A and Table 3). However, saccharin preference was scarcely affected by a lack of AHR (Fig. 7B). These results strongly suggest that, also in females, TCDD targets AHR activation to reduce pituitary gonadotropins during the fetal period, leading to disorders in sexual maturation after reaching adulthood. 


\section{Discussion}

Although there is much evidence that AHR plays a key role in a variety of toxic effects of dioxins $[4,5]$, the importance of AHR for dioxin-induced defects in sexual dimorphism of the next generations has remained largely unknown. Based on our previous findings that TCDD damages steroidogenesis of the pituitary-gonadal axis during the fetal stage to imprint defects in sexual behaviors after reaching adulthood [22], the present study demonstrated that activation of AHR is indispensable for TCDD-induced defects in sexual maturation at adulthood by targeting the fetal pituitary-gonadal axis. In particular, maternal treatment with TCDD reduced the pituitary synthesis of gonadotropins and testicular steroidogenesis in wild-type fetuses, while AHR-KO fetuses were insensitive to such treatment. These AHR-dependent effects seem to be transient during the fetal stage, because the reduced level of gonadotropins disappeared after reaching maturity. However, sexually-dimorphic behaviors at adulthood, such as masculine sexual behavior and saccharin preference, were negatively affected by fetal exposure to TCDD only in wild-type offspring. Our current findings provide new insight into the toxicological significance of AHR in the next generations.

Fetal Leydig cells in rodents start to differentiate around GD11.5, and increase during the fetal stage [29]. Consequently, the fetal production of testicular testosterone occurs at approximately GD15, and its concentration increases sharply until GD18, while an increase in plasma LH does not occur until GD19.5 [30, 31]. Therefore, it has been assumed that fetal Leydig cells predominantly produce sex-steroids before GD19.5 in an LH-independent manner [29], while they can respond to LH to produce 
testosterone during the late fetal stage [32]. Although it has been unclear whether TCDD and the AHR influence fetal Leydig cells, our previous studies have found that treating pregnant rats at GD15 with TCDD dramatically attenuate the expression of testicular StAR/CYP17 mRNAs only during GD20.5 and PND2 [21, 23]. Also, the closely concomitant reduction in the expression of pituitary LH was observed without the reduced expression of LHR mRNA [20, 23]. In contrast, maternal exposure to TCDD had little effects on the expression of StAR/CYP17 in the fetal testis before GD19.5 [23]. Taking these factors into consideration, it is possible that TCDD initially targets the pituitary LH during the late fetal stage to attenuate testosterone formation at the final stages of gestation without affecting steroidogenesis in Leydig cells which are independent on LH stimulation. In support of this, giving equine chorionic gonadotropin, an LH-like hormone, to TCDD-exposed fetuses completely restores not only a reduction in the testicular expression at GD20 of steroidogenic proteins but also defects in sexual behavior after reaching adulthood [22].

In addition to the contribution of AHR on dioxin-produced sexual immaturity, the present study revealed that knocking out AHR attenuated not only steroidogenesis in the pituitary-gonadal axis during the fetal stage but also masculine sexual behavior of the offspring after reaching maturity. Similarly, it has been reported that a reduced expression of gonadotropin mRNAs is observed in Ahr-KO mice at the early neonatal stage [33], although its mechanism and significance remain unknown. It has long been known that sex-steroids produced by the testis during the fetal and neonatal period stimulate the immature male brain to cause sexual differentiation of neurons including masculinization and defeminization $[34,35]$. More specifically, owing to the above 
process triggered by sex-steroids, the gender-specific structure and cellular components of neurons are permanently determined, and all animals can acquire gender-specific phenotypes such as sexual behaviors after reaching adulthood [36, 37]. Therefore, it is conceivable that AHR signaling is important for sex-steroid biosynthesis during the fetal period due to regulation of gonadotropin syntheses, which triggers the brain sexual differentiation to acquire of sexually-dimorphic phenotypes after reaching maturity. In support of this, AHR deletion had no effect on some behavioral indices including the locomotor activity and anxiety-related behavior in male offspring, suggesting that the AHR signaling preferentially targets the formation of sexual dimorphism due to the stimulation of sex-steroids at the fetal stage. Some researches have demonstrated that AHR is important for physiological functions including immunity [38-40] and lipid metabolism [41, 42], and both over-activation and inactivation of AHR leads to impaired physiology $[39,42]$. Thus, the constitutive activity of AHR can be closely counterbalanced to maintain homeostasis. In relation to this, the present study found that AHR deletion as well as AHR activation mediated by TCDD resulted in similar effects including down-regulation of fetal steroidogenesis. These pieces of information support the alternative possibility that the constitutive function of AHR is necessary for the pituitary synthesis of gonadotropins during the fetal period, and strong exogenous ligands such as TCDD deregulate this intrinsic function to attenuate the fetal expression of steroidogenic proteins. Additionally, it is suggested that such degeneration of fetal steroidogenesis of pituitary-gonadal axis through the dysfunction of the constitutive role of AHR results in the abnormal brain differentiation after reaching adulthood. 
The mechanism whereby the absence of AHR defines the reduced expression of gonadotropins in fetuses remains unclear. We have reported that the TCDD-produced induction of HDACs contributes to the reduction in LH $\beta$ level [21], and this study re-confirmed this and revealed that maternal exposure to TCDD induced the expression of HDAC5 and HDAC7 mRNA in an AHR-dependent manner. As a computer-assisted survey suggested the presence of several XRE motifs at 5'-upstream regions of these HDACs, it is reasonable to consider that AHR-TCDD complex induces the expression of HDACs following binding to their XREs. However, it is unlikely that HDACs are associated with the effect of AHR deletion on the transcription of $\mathrm{LH} \beta$, because AHR-KO fetuses did not exhibit any change in the expression of pituitary HDACs. In contrast, deleting AHR as well as TCDD exposure to wild-type rats suppressed the fetal expression of pituitary GnRHR mRNA (see Fig. 3A). Therefore, this is a possible reason for the reduced expression of gonadotropins in AHR-KO fetuses. It has been reported that the expression of AHR mRNA is significantly induced during cell differentiation [43]. The synthesis of LH and FSH starts from the late fetal stage when gonadotropes, LH/FSH-producing cells, differentiate and mature to acquire GnRHR [44], and a large population of gonadotropes expresses AHR in rats [45]. Considering these findings, it is possible that AHR signaling is involved in normal differentiation and development of gonadotropes during the fetal period.

The expression of testicular StAR and pituitary LH in AHR-KO fetuses tended to be elevated by maternal exposure to TCDD, and the similar trend was observed in terms of masculine sexual behaviors after they reach adulthood. Although TCDD preferentially targets the AHR, it may also affect other receptors with smaller extent. A previous 
report has shown that, in AHR-deficient lung cells, TCDD weakly bind to estrogen receptors (ERs) to block estrogen activity [46]. Estrogens directly down-regulate the

transcription of gonadotropin subunits in the pituitary [47]. Thus, exposing TCDD to the AHR-KO fetal pituitary may block ER-dependent suppression of LH synthesis due to affecting ERs, resulting in an apparent increase by TCDD in LH/StAR was observed in AHR-KO rats. Further studies focusing on ER activity during the critical period will be useful to understand the role of AHR in the regulation of gonadotropin production.

In conclusion, this study provides novel evidence that AHR is a driving force for the dioxin-produced suppression of the fetal pituitary-gonadal axis to cause the impairment of sexual dimorphism after reaching adulthood. Likewise, we found that AHR signaling is required for sexual maturation due to up-regulation of the pituitary synthesis of gonadotropins during the fetal stage. Further studies to clarify the detailed physiological and toxicological aspects of AHR during the fetal period need to be conducted to improve health and development of the next generations.

\section{Acknowledgements}

This work was supported by grants from the Uehara Memorial Foundation, the Japan Society for the Promotion of Science [Scientific Research (S) 24221004], and the Ministry of Health, Labor and Welfare, Japan [Research on Food Safety (H24-Designated Research-014 and H27-Designated Research-017)]. 


\section{Author contribution}

Participated in research design: Hattori, Takeda, Nakamura, Nishida,

Shioji, Fukumitsu, Yamada and Ishii.

Conducted experiments: Hattori, Takeda, Nakamura, Nishida,

Shioji, and Fukumitsu.

Contributed new reagents or analytic tools: Hattori, Takeda, Nakamura, Nishida, Shioji, and Fukumitsu.

Performed data and analysis: Hattori, Takeda, and Nakamura

Wrote or contributed to the writing of the manuscript: Hattori, Takeda, and Ishii 


\section{References}

[1] Gasiewicz TA (1991) in 18.5 TCDD and other acnegenic materials, ed. by Hayes Jr. WJ, Laws ER, Handbook of pesticide toxicology, vol. 3, Classes of pesticides, Academic Press, San Diego, pp. $1217-1269$

[2] Pirkle JL, Wolfe WH, Patterson DG, Needham LL, Michalek JE, Miner JC, Peterson MR, Phillips DL (1989) Estimates of the half-life of 2,3,7,8-tetrachlorodibenzo-p-dioxin in Vietnam Veterans of Operation Ranch Hand. J Toxicol Environ Health. 27: 165-171

[3] Poland A, Knutson JC (1982) 2,3,7,8-tetrachlorodibenzo-p-dioxin and related halogenated aromatic hydrocarbons: examination of the mechanism of toxicity. Annu Rev Pharmacol Toxicol. 22: $517-554$

[4] Fernandez-Salguero PM, Hilbert DM, Rudikoff S, Ward JM, Gonzalez FJ (1996) Aryl-hydrocarbon mice are receptor-deficient to 2,3,7,8-tetrachlorodibenzo- $p$-dioxin-induced toxicity. Toxicol Appl Pharmacol. 140: 173-179

[5] Harrill JA, Hukkanen RR, Lawson M, Martin G, Gilger B, Soldatow V, Lecluyse EL, Budinsky RA, Rowlands JC, Thomas RS. (2013) Knockout of the aryl hydrocarbon receptor results in distinct hepatic and renal phenotypes in rats and mice. Toxicol Appl Pharmacol. 272: 503-518

[6] Hankinson O (1995) The aryl hydrocarbon receptor complex. Annu Rev Pharmacol Toxicol. 35: $307-340$

[7] Denison MS, Fisher JM, Whitlock JP Jr (1989) Protein-DNA interactions at recognition sites for the dioxin-Ah receptor complex. J Biol Chem. 264: 16478-16482

[8] Whitlock JP Jr (1999) Induction of cytochrome P4501A1. Annu Rev Pharmacol Toxicol. 39: $103-125$

[9] Peterson RE, Theobald HM, Kimmel GL (1993) Developmental and reproductive toxicity of dioxins and related compounds: cross-species comparisons. Crit Rev Toxicol. 23: 283-335

[10] Nebert D, Dillmann I (1972) Embryotoxic effects in mice treated wtih 2,4,5-trichlorophenoxyacetic acid and 2,3,7,8-tetrachlorodibenzo- $p$-dioxin. Naunyn Schmiedebergs Arch Pharmacol. 272: 243-264

[11] Gray LE Jr, Kelce WR, Monosson E, Ostby JS, Birnbaum LS (1995) Exposure to TCDD during development permanently alters reproductive function in male Long Evans rats and hamsters: reduced ejaculated and epididymal sperm numbers and sex accessory gland weights in offspring with normal androgenic status. Toxicol Appl Pharmacol. 131: 108-118

[12] Faqi AS, Dalsenter PR, Merker HJ, Chahoud I (1998) Reproductive toxicity and tissue concentrations of low doses of 2,3,7,8-tetrachlorodibenzo- $p$-dioxin in male offspring rats exposed throughout pregnancy and lactation. Toxicol Appl Pharmacol. 150: 383-392

[13] Amin S, Moore RW, Peterson RE, Schantz SL. (2000) Gestational and lactational exposure to 
TCDD or coplanar PCBs alters adult expression of saccharin preference behavior in female rats. Neurotoxicol Teratol. 22: 675-682

[14] Guo YL, Hsu PC, Hsu CC, Lambert GH (2000) Semen quality after prenatal exposure to polychlorinated biphenyls and dibenzofurans. Lancet. 356: 1240-1241

[15] Grandjean P, Grønlund C, Kjær IM, Jensen TK, Sørensen N, Andersson AM, Juul A, Skakkebæk NE, Budtz-Jørgensen E, Weihe P (2012) Reproductive hormone profile and pubertal development in 14-year-old boys prenatally exposed to polychlorinated biphenyls. Reprod Toxicol. 34: 498-503

[16] Tsukimori K, Uchi H, Tokunaga S, Yasukawa F, Chiba T, Kajiwara J, Hirata T, Furue M (2013) Blood levels of PCDDs, PCDFs, and coplanar PCBs in Yusho mothers and their descendants: association with fetal Yusho disease. Chemosphere. 90: 1581-1588

[17] Winneke G, Ranft U, Wittsiepe J, Kasper-Sonnenberg M, Fürst P, Krämer U, Seitner G, Wilhelm M (2014) Behavioral sexual dimorphism in school-age children and early developmental exposure to dioxins and PCBs: a follow-up study of the Duisburg Cohort. Environ Health Perspect. 122: 292-298

[18] Hurst CH, DeVito MJ, Setzer RW, Birnbaum LS (2000) Acute administration of 2,3,7,8-tetrachlorodibenzo- $p$-dioxin (TCDD) in pregnant Long Evans rats: association of measured tissue concentrations with developmental effects. Toxicol Sci. 53: 411-420

[19] Chen CY, Hamm JT, Hass JR, Birnbaum LS (2001) Disposition of polychlorinated dibenzo-p-dioxins, dibenzofurans, and non-ortho polychlorinated biphenyls in pregnant long evans rats and the transfer to offspring. Toxicol Appl Pharmacol. 173: 65-88

[20] Mutoh J, Taketoh J, Okamura K, Kagawa T, Ishida T, Ishii Y, Yamada H (2006) Fetal pituitary gonadotropin as an initial target of dioxin in its impairment of cholesterol transportation and steroidogenesis in rats. Endocrinology. 147: 927-936

[21] Takeda T, Fujii M, Taura J, Ishii Y, Yamada H (2012) Dioxin silences gonadotropin expression in perinatal pups by inducing histone deacetylases: a new insight into the mechanism for the imprinting of sexual immaturity by dioxin. J Biol Chem. 287: 18440-18450

[22] Takeda T, Matsumoto Y, Koga T, Mutoh J, Nishimura Y, Shimazoe T, Ishii Y, Ishida T, Yamada H (2009) Maternal exposure to dioxin disrupts gonadotropin production in fetal rats and imprints defects in sexual behavior. J Pharmacol Exp Ther. 329: 1091-1099

[23] Takeda T, Fujii M, Hattori Y, Yamamoto M, Shimazoe T, Ishii Y, Himeno M, Yamada H (2014) Maternal exposure to dioxin imprints sexual immaturity of the pups through fixing the status of the reduced expression of hypothalamic gonadotropin-releasing hormone. Mol Pharmacol. 85: 74-82

[24] Takeda T, Komiya Y, Koga T, Ishida T, Ishii Y, Kikuta Y, Nakaya M, Kurose H, Yokomizo T, Shimizu T, Uchi H, Furue M, Yamada H (2017) Dioxin-induced increase in leukotriene B4 
biosynthesis through the aryl hydrocarbon receptor and its relevance to hepatotoxicity owing to neutrophil infiltration. J Biol Chem. 292: 10586-10599

[25] Taura J, Takeda T, Fujii M, Hattori Y, Ishii Y, Kuroki H, Tsukimori K, Uchi H, Furue M, Yamada $\mathrm{H}$ (2014) 2,3,4,7,8-Pentachlorodibenzofuran is far less potent than 2,3,7,8-tetrachlorodibenzo- $p$-dioxin in disrupting the pituitary-gonad axis of the rat fetus. Toxicol Appl Pharmacol. 281: 48-57

[26] Matsumoto Y, Ishida T, Takeda T, Koga T, Fujii M, Ishii Y, Fujimura Y, Miura D, Wariishi H, Yamada H (2010) Maternal exposure to dioxin reduces hypothalamic but not pituitary metabolome in fetal rats: a possible mechanism for a fetus-specific reduction in steroidogenesis. $\mathrm{J}$ Toxicol Sci. 35: 365-373

[27] Hattori Y, Takeda T, Fujii M, Taura J, Ishii Y, Yamada H (2014) Dioxin-induced fetal growth retardation: the role of a preceding attenuation in the circulating level of glucocorticoid. Endocrine. 47: 572-580

[28] Takeda T, Matsuo Y, Nishida K, Fujiki A, Hattori Y, Koga T, Ishii Y, Yamada H (2017) $\alpha$-Lipoic acid potentially targets AMP-activated protein kinase and energy production in the fetal brain to ameliorate dioxin-produced attenuation in fetal steroidogenesis. J Toxicol Sci. 42: 13-23

[29] Teerds KJ, Huhtaniemi IT (2015) Morphological and functional maturation of Leydig cells: from rodent models to primates. Hum Reprod Update. 21:310-328

[30] Habert R and Picon R (1982) Control of testicular steroidogenesis in foetal rat: effect of decapitation on testosterone and plasma luteinizing hormone-like activity. Acta Endocrinol. 99:466-473

[31] El-Gehani F, Zhang FP, Pakarinen P, Rannikko A, and Huhtaniemi I (1998) Gonadotropin-independent regulation of steroidogenesis in the fetal rat testis. Biol Reprod. $58: 116-123$

[32] Habert R, Brignaschi P (1991) Developmental changes in in vitro testosterone production by dispersed Leydig cells during fetal life in rats. Arch Androl. 27:65-71

[33] Moran TB, Brannick KE, Raetzman LT (2012) Aryl-hydrocarbon receptor activity modulates prolactin expression in the pituitary. Toxicol Appl Pharmacol. 265: 139-145Biljes D, Hammerschmidt-Kamper C, Kadow S, Diel P, Weigt C, Burkart V, Esser C (2015) Impaired glucose and lipid metabolism in ageing aryl hydrocarbon receptor deficient mice. EXCLI J. 14: 1153-1163

[34] Whalen RE, Edwards DA (1967) Hormonal determinants of the development of masculine and feminine behavior in male and female rats. Anat Rec. 157: 173-180

[35] MacLusky NJ, Naftolin F (1981) Sexual differentiation of the central nervous system. Science. 211: 1294-1302

[36] Morris JA, Jordan CL, Breedlove SM (2004) Sexual differentiation of the vertebrate nervous 
system. Nat Neurosci. 7: 1034-1039

[37] McCarthy MM (2008) Estradiol and the developing brain. Physiol Rev. 88: 91-124

[38] Bock KW, Köhle C. (2006) Ah receptor: dioxin-mediated toxic responses as hints to deregulated physiologic functions. Biochem Pharmacol. 72: 393-404

[39] Schiering C, Wincent E, Metidji A, Iseppon A, Li Y, Potocnik AJ, Omenetti S, Henderson CJ, Wolf CR, Nebert DW, Stockinger B. (2017) Feedback control of AHR signalling regulates intestinal immunity. Nature. 542: 242-245

[40] Schiering C, Vonk A, Das S, Stockinger B, Wincent E. (2018) Cytochrome P4501-inhibiting chemicals amplify aryl hydrocarbon receptor activation and IL-22 production in T helper 17 cells. Biochem Pharmacol. in press

[41] Minami K, Nakajima M, Fujiki Y, Katoh M, Gonzalez FJ, Yokoi T (2008) Regulation of insulin-like growth factor binding protein-1 and lipoprotein lipase by the aryl hydrocarbon receptor. J Toxicol Sci. 33: 405-13

[42] Biljes D, Hammerschmidt-Kamper C, Kadow S, Diel P, Weigt C, Burkart V, Esser C (2015) Impaired glucose and lipid metabolism in ageing aryl hydrocarbon receptor deficient mice. EXCLI J. 14: 1153-1163

[43] Hayashi S, Okabe-Kado J, Honma Y, Kawajiri K (1995) Expression of Ah receptor (TCDD receptor) during human monocytic differentiation. Carcinogenesis. 16: 1403-1409

[44] Aubert ML, Begeot M, Winiger BP, Morel G, Sizonenko PC, Dubois PM (1985) Ontogeny of hypothalamic luteinizing hormone-releasing hormone $(\mathrm{GnRH})$ and pituitary $\mathrm{GnRH}$ receptors in fetal and neonatal rats. Endocrinology. 116: 1565-1576

[45] Cao J, Patisaul HB, Petersen SL (2011) Aryl hydrocarbon receptor activation in lactotropes and gonadotropes interferes with estradiol-dependent and -independent preprolactin, glycoprotein alpha and luteinizing hormone beta gene expression. Mol Cell Endocrinol. 333: 151-159

[46] Kuo LC, Cheng LC, Lin CJ, Li LA (2013) Dioxin and estrogen signaling in lung adenocarcinoma cells with different aryl hydrocarbon receptor/estrogen receptor $\alpha$ phenotypes. Am J Respir Cell Mol Biol. 49: 1064-1073

[47] Gharib SD, Bowers SM, Need LR, Chin WW (1986) Regulation of rat luteinizing hormone subunit messenger ribonucleic acids by gonadal steroid hormones. J Clin Invest. 77: 582-589 


\section{Figure Legends}

Fig. 1 Experimental design of this study and confirmation of AHR deletion. (A and B) Pregnant AHR-Het rats obtained by mating with AHR-Het males were treated with TCDD (1 $\mu \mathrm{g} / \mathrm{kg}$, orally at GD15). After determining the genotypes of their littermates (see panel B), three different genotypes included in a littermate were used for tissue collections and behavior tests. (C) The relative levels of AHR and CYP1A1 mRNAs in the fetal pituitary. Each bar represents the mean \pm S.E.M. of 7-9 fetuses. The number of fetuses in each group is as follows. Control WT: $\mathrm{N}=7$, Control Het: $\mathrm{N}=8$, Control KO: $\mathrm{N}=8$, TCDD WT: $\mathrm{N}=8$, TCDD Het: $\mathrm{N}=8$ and TCDD KO: $\mathrm{N}=9$. These fetuses were removed from 5 Control and 7 TCDD-treated dams. Significantly different from the WT control: *, p<0.05. Abbreviations: WT, wild-type; Het, heterozygote; KO, AHR-knockout; ND, not detectable.

Fig. 2 Disappearance of TCDD-produced reduction on the pituitary expression of gonadotropin mRNAs and serum level of $\mathrm{LH}$ in male AHR-KO fetuses. (A) The relative levels of gonadotropin mRNAs in the male fetal pituitary. Each bar represents the mean \pm S.E.M. of 8-10 fetuses. The number of fetuses in each group is as follows. Control WT: $\mathrm{N}=10$, Control Het: $\mathrm{N}=8$, Control KO: $\mathrm{N}=8$, TCDD WT: N=8, TCDD Het: $\mathrm{N}=8$ and TCDD KO: $\mathrm{N}=9$. These fetuses were removed from 5 Control and 7 TCDD-treated dams. (B) The serum concentration of LH in male fetuses. Each bar represents the mean \pm S.E.M. of 5-8 fetuses. The number of fetuses in each group is as follows. Control WT: N=8, Control Het: N=8, Control KO: N=7, TCDD WT: N=6, TCDD Het: $\mathrm{N}=5$ and TCDD KO: $\mathrm{N}=6$. These fetuses were removed from 5 Control and 6 TCDD-treated dams. Significantly different from the WT control: * ${ }^{*} \mathrm{p}<0.05$. NS, not significant.

Fig. 3 The effect of TCDD on the expression of mRNAs coding for pituitary 
HDACs and GnRHR and hypothalamic GnRH, GnIH and Kiss1 in male wild-type and AHR-KO fetuses. (A) The relative levels of HDACs and GnRHR mRNAs in the male fetal pituitary. Each bar represents the mean \pm S.E.M. of 8-13 fetuses. The number of fetuses in each group is as follows. Control WT: N=13, Control KO: N=8, TCDD WT: $N=11$ and TCDD KO: $N=8$. These fetuses were removed from 5 Control and 7 TCDD-treated dams. (B) The relative levels of GnRH, GnIH and Kiss 1 mRNAs in male fetal hypothalamus. Each bar represents the mean \pm S.E.M. of 4 fetuses. The number of fetuses in each group is as follows. Control WT: $\mathrm{N}=4$, Control KO: $\mathrm{N}=4$, TCDD WT: $\mathrm{N}=4$ and TCDD KO: $\mathrm{N}=4$. These fetuses were removed from 4 Control and 4 TCDD-treated dams. Significantly different from the WT control: ${ }^{*}, p<0.05$. NS, not significant.

Fig. 4 Disappearance of the TCDD-produced reduction in the testicular expression of mRNAs coding for StAR and CYP17, StAR protein and the serum level of testosterone in male AHR-KO fetuses. (A) The relative levels of StAR and CYP17 mRNAs in the fetal testis. Each bar represents the mean \pm S.E.M. of 4-5 fetuses. The number of fetuses in each group is as follows. Control WT: $\mathrm{N}=4$, Control KO: $\mathrm{N}=5$, TCDD WT: $\mathrm{N}=5$ and TCDD KO: $\mathrm{N}=5$. These fetuses were removed from 4 Control and 5 TCDD-treated dams. (B) The relative levels of StAR protein in the fetal testis. CW, Control WT; TW, TCDD WT; CKO, Control KO; and TKO, TCDD KO. Each bar represents the mean \pm S.E.M. of 3-8 fetuses. The number of fetuses in each group is as follows. Control WT: N=8, Control KO: N=6, TCDD WT: N=6 and TCDD KO: N=3. These fetuses were removed from 5 Control and 6 TCDD-treated dams. (C) The serum concentration of testosterone in male fetuses. Each bar represents the mean \pm S.E.M. of 4-8 fetuses. The number of fetuses in each group is as follows. Control WT: $\mathrm{N}=5$, Control KO: $\mathrm{N}=8$, TCDD WT: $\mathrm{N}=6$ and TCDD KO: $\mathrm{N}=4$. These fetuses were removed from 5 Control and 6 TCDD-treated dams. Significantly different from the WT control: *, $\mathrm{p}<0.05$. NS, not significant. 
Fig. 5 The effect of TCDD on the pituitary expression of gonadotropin mRNAs, the serum level of $\mathrm{LH}$ and the masculine sexual behavior in male wild-type and AHR-KO offspring after reaching adulthood. (A) The relative levels of gonadotropin mRNAs in the pituitary of male offspring at 13 weeks of age. Each bar represents the mean \pm S.E.M. of 5-6 rats. The number of rats in each group is as follows. Control WT: $\mathrm{N}=5$, Control KO: $\mathrm{N}=6$, TCDD WT: $\mathrm{N}=6$ and TCDD KO: $\mathrm{N}=6$. (B) The serum concentration of LH in male offspring at 13 weeks of age. Each bar represents the mean \pm S.E.M. of 5 rats. The number of rats in each group is as follows. Control WT: $\mathrm{N}=5$, Control KO: $\mathrm{N}=5$, TCDD WT: $\mathrm{N}=5$ and TCDD KO: $\mathrm{N}=5$. (C) Number of intromissions and latency until first intromission were observed in male offspring at 10-11 weeks of age. Each bar represents the mean \pm S.E.M. of 6-16 rats. The number of rats in each group is as follows. Control WT: $\mathrm{N}=16$, Control KO: $\mathrm{N}=14$, TCDD WT: $\mathrm{N}=9$ and TCDD KO: $\mathrm{N}=6$. Significantly different from the WT control: * $\mathrm{p}<0.05$. NS, not significant.

Fig. 6 Absence of the effect of AHR ablation on the locomotor activity and anxiety-related behaviors in male offspring at 5 weeks of age. A locomotor activity and anxiety-related behavior were assessed by an open field test for $5 \mathrm{~min}$. (A) The total distance traveling in the field was measured. (B) The percentage of time spent in the center area to total time and the number of entries in the center area are assessed as indices of anxiety-related behaviors. Each bar represents the mean \pm S.E.M. of 5-8 rats. The number of rats in each group is as follows. Control WT: $\mathrm{N}=8$ and Control KO: $\mathrm{N}=5$.

Fig. 7 Disappearance of TCDD-produced attenuation in the expression of gonadotropin mRNAs at the fetal stage and saccharin preference at adulthood in female AHR-KO offspring. (A) The relative levels of gonadotropin mRNAs in the female fetal pituitary. Each bar represents the mean \pm S.E.M. of 5-6 fetuses. The number of fetuses in each group is as follows. Control WT: $\mathrm{N}=6$, Control Het: $\mathrm{N}=6$, 
Control KO: $\mathrm{N}=5$, TCDD WT: $\mathrm{N}=6$, TCDD Het: $\mathrm{N}=6$ and TCDD KO: $\mathrm{N}=6$. These fetuses were removed from 5 Control and 6 TCDD-treated dams. (B) Saccharin preference was examined in female offspring at 9 weeks of age. Each bar represents the mean \pm S.E.M. of 5-8 rats. The number of rats in each group is as follows. Control WT: $\mathrm{N}=5$, Control KO: $\mathrm{N}=8$, TCDD WT: $\mathrm{N}=8$ and TCDD KO: $\mathrm{N}=8$. Significantly different from the WT control: *, $\mathrm{p}<0.05$. 
Table 1 Primers used for real-time RT-PCR

\begin{tabular}{|c|c|c|c|c|}
\hline Target & Forward primer $\left(5^{\prime}->3^{\prime}\right)$ & Reverse primer $\left(5^{\prime}->3^{\prime}\right)$ & Size (bp) & Accession No. \\
\hline$\beta$-actin & CACCATGTACCCAGGCATCGC & AGCCACCAATCCACACAGAG & 246 & V01217 \\
\hline AHR & ACAGTAAAGCCCGTCCCTGC & GGCGGTCTAACTCTGTGTTCAG & 85 & NM_013149 \\
\hline CYP1A1 & CCATGACCAGGAACTATGGG & ATGACCTTCTCACTCAGGTG & 99 & NM_012540 \\
\hline LH $\beta$ & AGAGAATGAGTTCTGCCCAGTCTG & TGGCAGTACTCGAACCATGC & 85 & J00749 \\
\hline $\mathrm{FSH} \beta$ & TCCAGTAGCCACTGAATGCC & TTCACCGAAGGAGCAGTAGC & 97 & M36804 \\
\hline HDAC5 & ATGAACAGCCAAGTGTCAGC & TCAGGAGCTTCATGGATTCC & 110 & NM_053450 \\
\hline HDAC7 & AGCAGGCTTGCAACAGCAAC & AGTTCTTGCTCCTGCTGTGC & 99 & XM_008765843 \\
\hline GnRHR & GGAACATCACTGTTCAGTGG & ATCCAGGCTAATCACCACCAT & 113 & NM_031038 \\
\hline GnRH & GGCAAGGAGGAGGATCAAAT & GCCAGGCATTCCTCTTCAATC & 121 & NM_012767 \\
\hline GnIH & TGGTTTGCCCCAGAAATCCC & AAGGACTGGCTGGAGGTTTC & 178 & NM_023952 \\
\hline kiss1 & CTGGCTTCTTGGCAGCTGCT & GCCAGGCATTAACGAGTTCC & 133 & NM_181692 \\
\hline StAR & ACACTTTGGGGAGATGCCTG & CGTGAGTTTGGTCTTTGAGG & 109 & U76419 \\
\hline CYP17 & GCACAATCCTGAGGTGAAGA & CTGATACGCAGCACTTCTCG & 135 & M31681 \\
\hline
\end{tabular}


Table 2 Effects of TCDD exposure to pregnant AHR-Het rats on the litter size, sex ratio, percentage AHR-KO offspring and body weight of offspring.

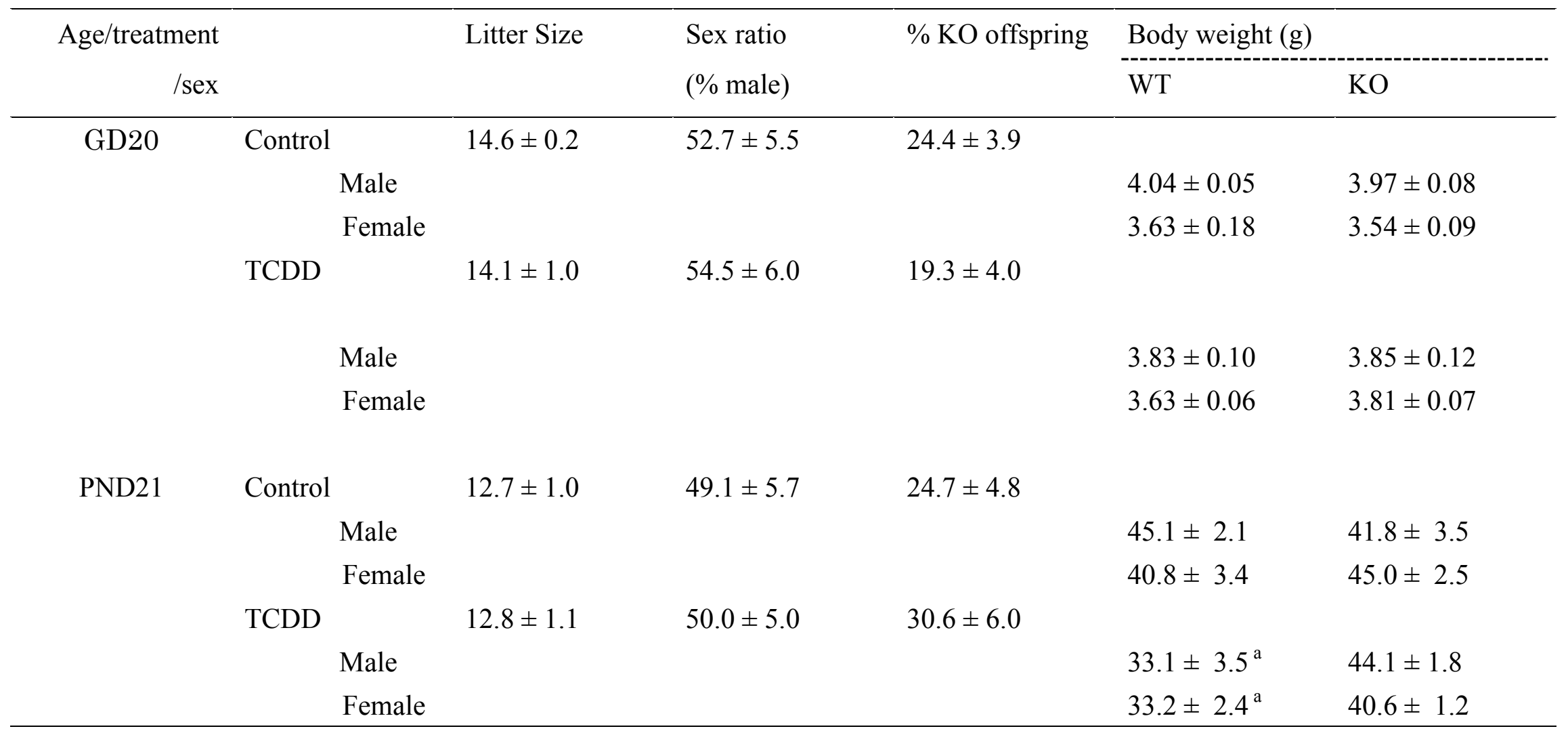

Pregnant AHR-Het rats at GD15 were orally treated with TCDD. The litter size, sex ratio, percentage of AHR-KO offspring and body weight of offspring were measured at GD20 and PND 21. Each value represents the mean \pm S.E.M. of 7 dams or 7-17 offspring. ${ }^{a}$ Significantly different from the WT control: $\mathrm{p}<0.05$. 
Table 3 Effect of TCDD exposure to pregnant AHR-Het rats on the body weight, anogenital distance (AGD) and urethrovaginal distance (UVD) of offspring after reaching maturity

\begin{tabular}{|c|c|c|c|c|c|c|c|}
\hline \multirow{2}{*}{$\begin{array}{r}\text { Age/treatment } \\
\qquad / \text { sex }\end{array}$} & & \multirow{2}{*}{$\begin{array}{l}\text { Body weigh } \\
\text { WT }\end{array}$} & \multirow{2}{*}{$\begin{array}{l}(\mathrm{g}) \\
\mathrm{KO} \\
\end{array}$} & \multicolumn{2}{|l|}{ AGD (\%) } & \multicolumn{2}{|l|}{ UVD (\%) } \\
\hline & & & & WT & $\mathrm{KO}$ & WT & $\mathrm{KO}$ \\
\hline \multirow[t]{6}{*}{ PND49 } & Control & & & & & & \\
\hline & Male & $248 \pm 6$ & $229 \pm 18$ & $17.2 \pm 0.3$ & $18.2 \pm 1.4$ & & \\
\hline & Female & $179 \pm 4$ & $185 \pm 4$ & $12.2 \pm 0.2$ & $11.1 \pm 0.2$ & $2.76 \pm 0.09$ & $2.41 \pm 0.07^{\mathrm{a}}$ \\
\hline & TCDD & & & & & & \\
\hline & Male & $202 \pm 10$ & $205 \pm 22$ & $18.9 \pm 0.6$ & $21.1 \pm 2.2$ & & \\
\hline & Female & $156 \pm 5^{\mathrm{a}}$ & $177 \pm 5$ & $11.7 \pm 0.2$ & $11.7 \pm 0.4$ & $2.02 \pm 0.06^{\mathrm{a}}$ & $2.55 \pm 0.10$ \\
\hline
\end{tabular}

Pregnant AHR-Het rats at GD15 were orally treated with TCDD. The body weight AGD and UVD of offspring were measured at PND49. AGD and UVD are shown as the value relative to the body weight (millimeter-to-gram percentage). Each value represents the

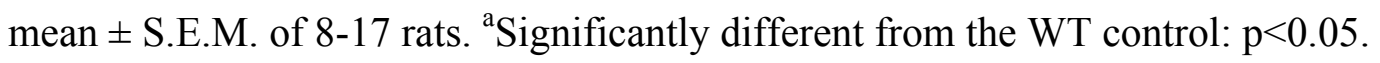




\section{Hattori et al., Fig. 1}
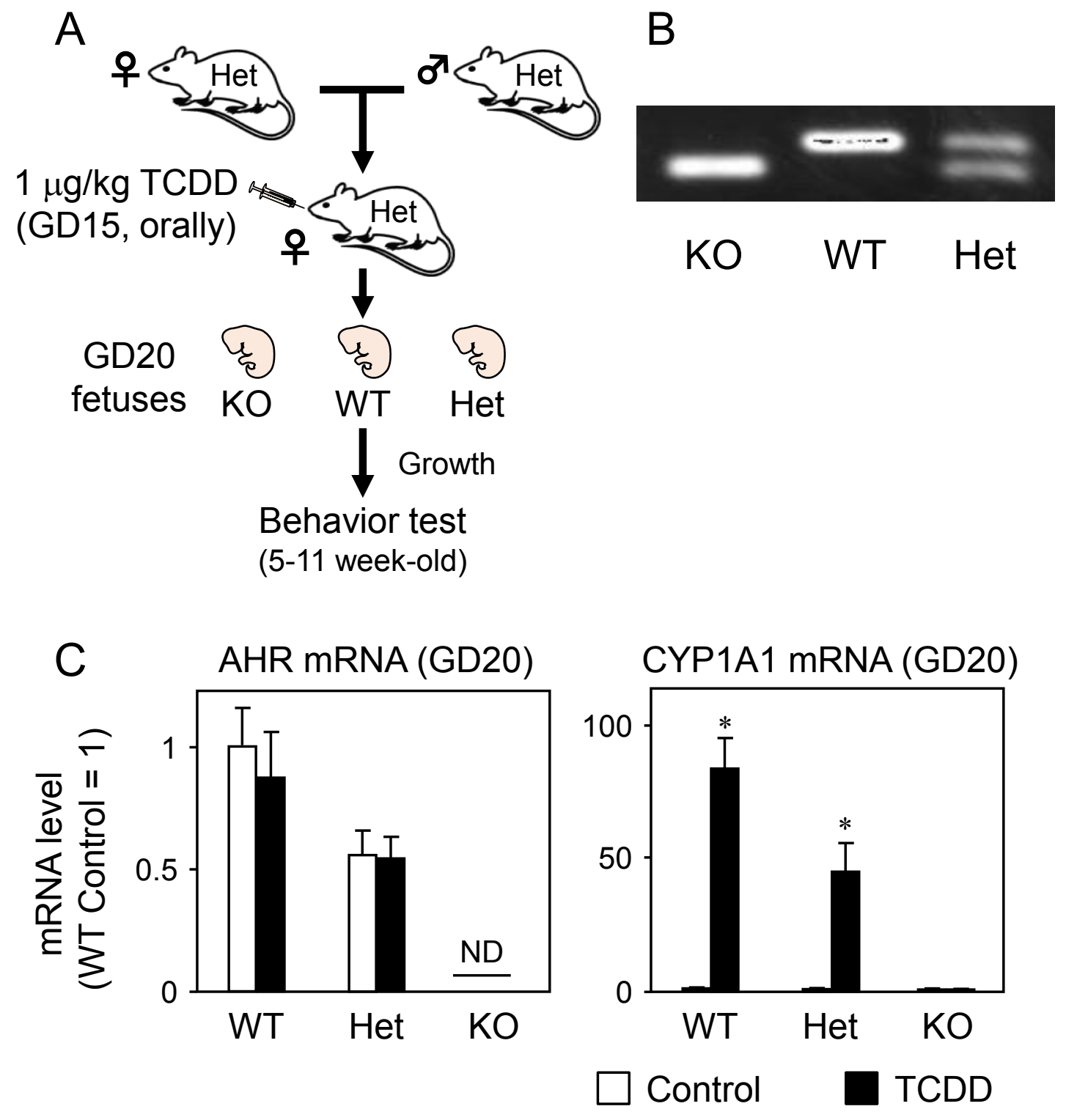
Hattori et al., Fig. 2

A

LH $\beta$ mRNA

(GD20)

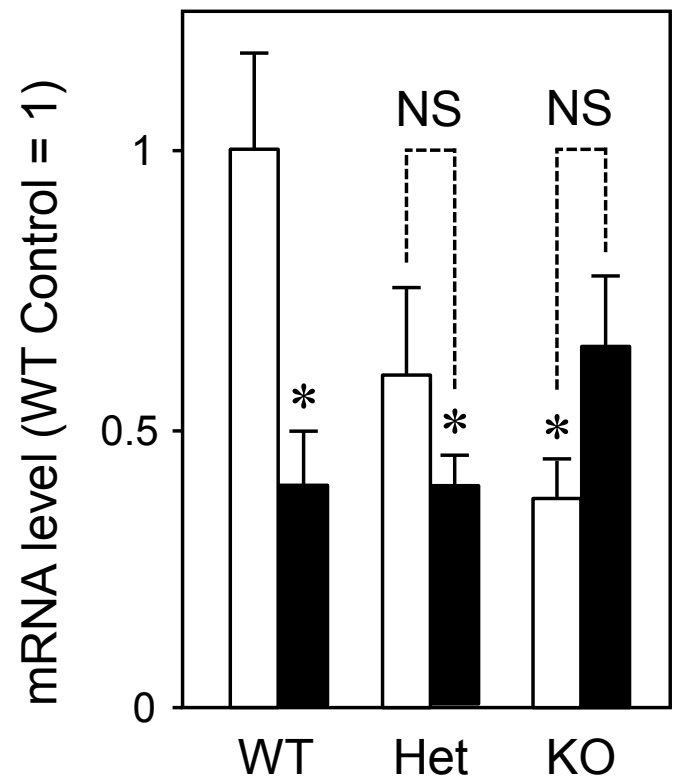

B

Serum LH

(GD20)

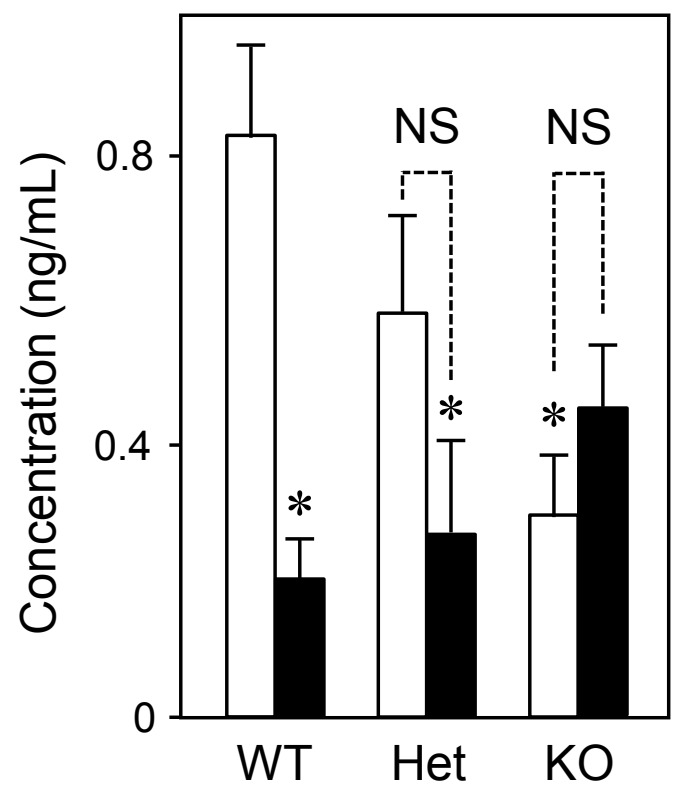

$\mathrm{FSH} \beta$ mRNA

(GD20)

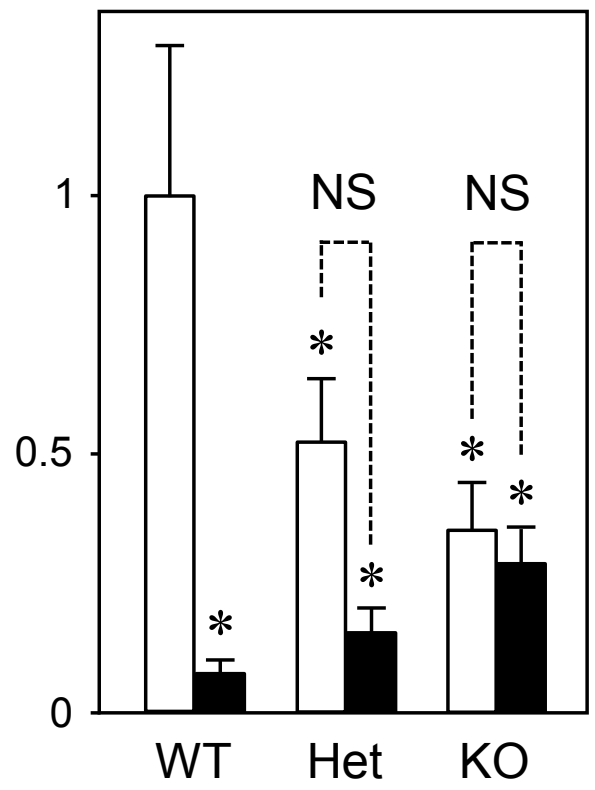




\section{Hattori et al., Fig. 3}

A

Male fetal pituitary at GD20
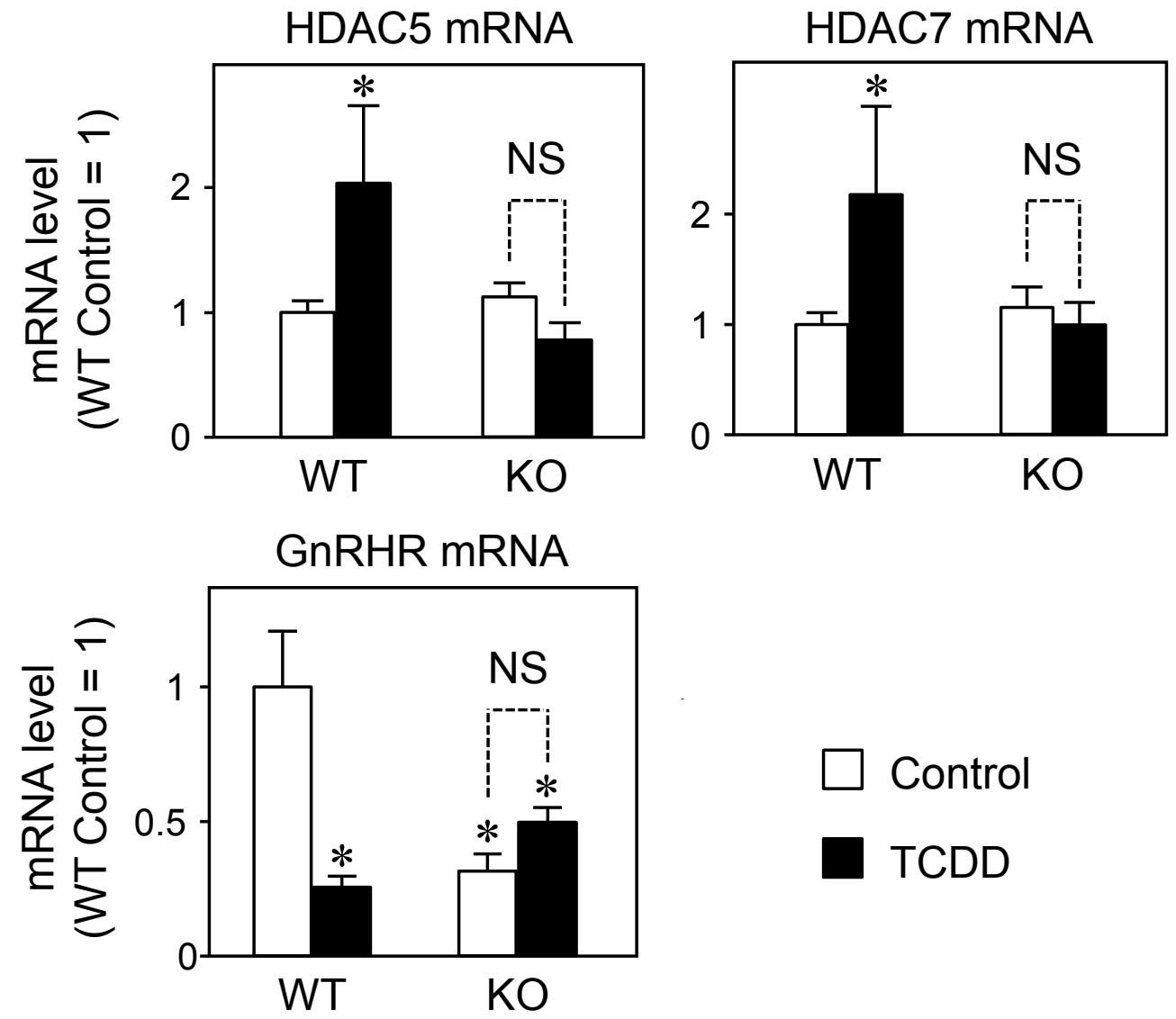

B

Male fetal hypothalamus at GD20
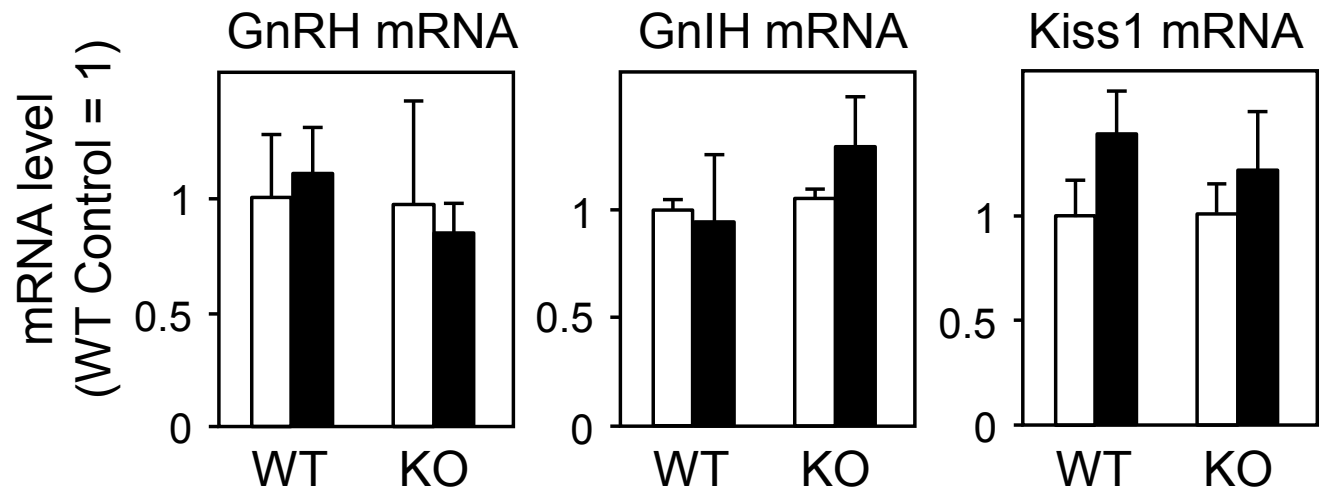
Hattori et al., Fig. 4
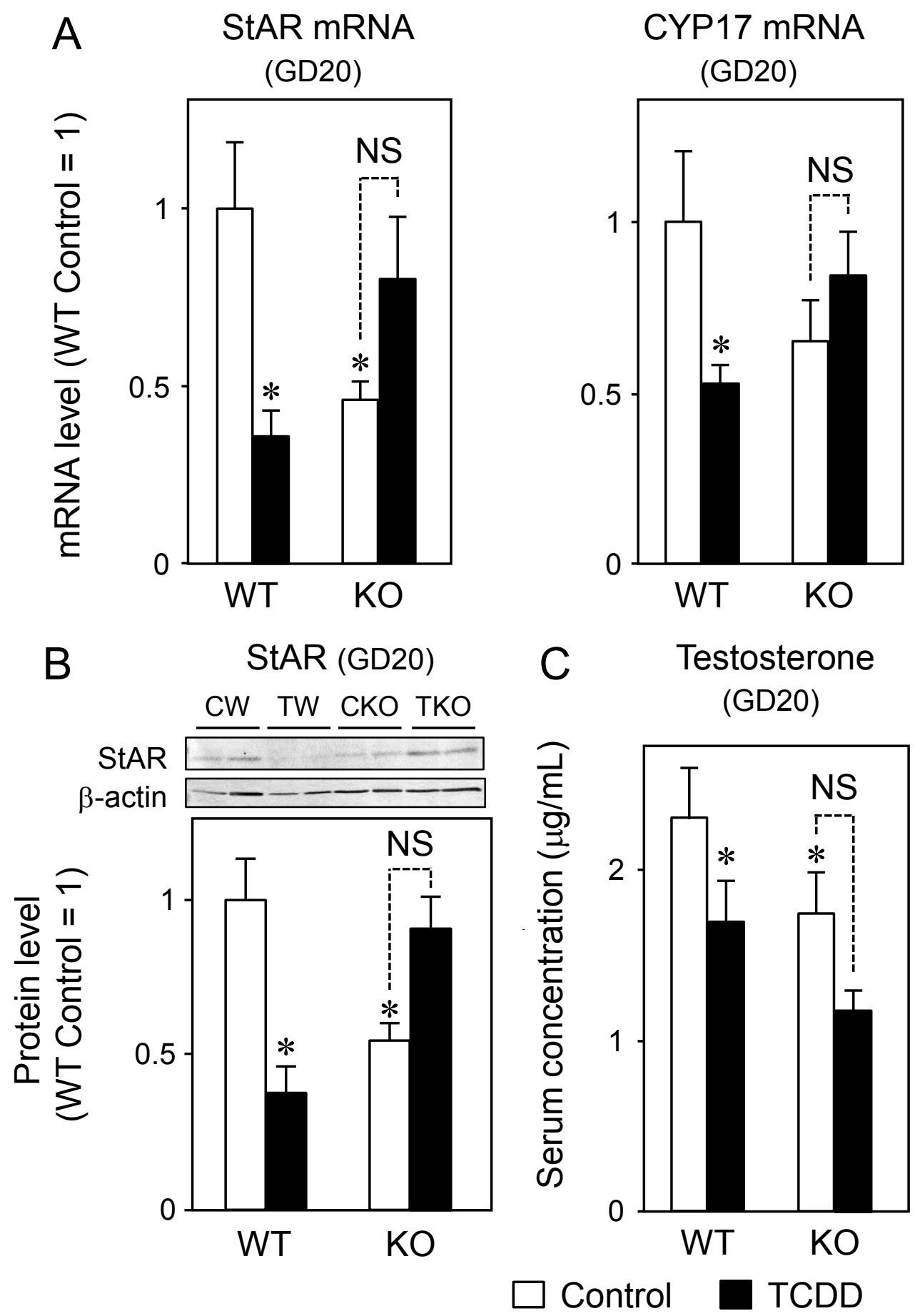


\section{Hattori et al., Fig. 5}
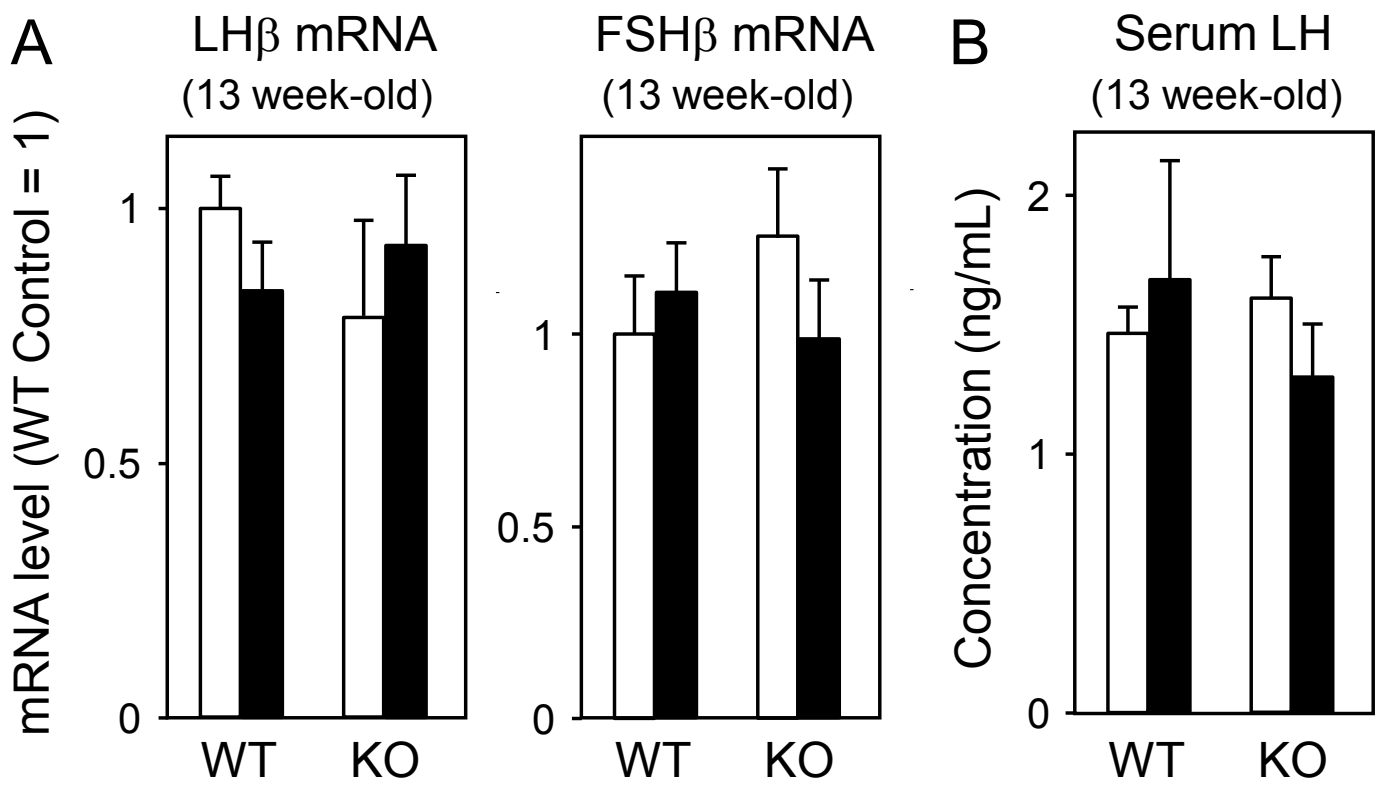

C Intromission

(10-11 week-old)

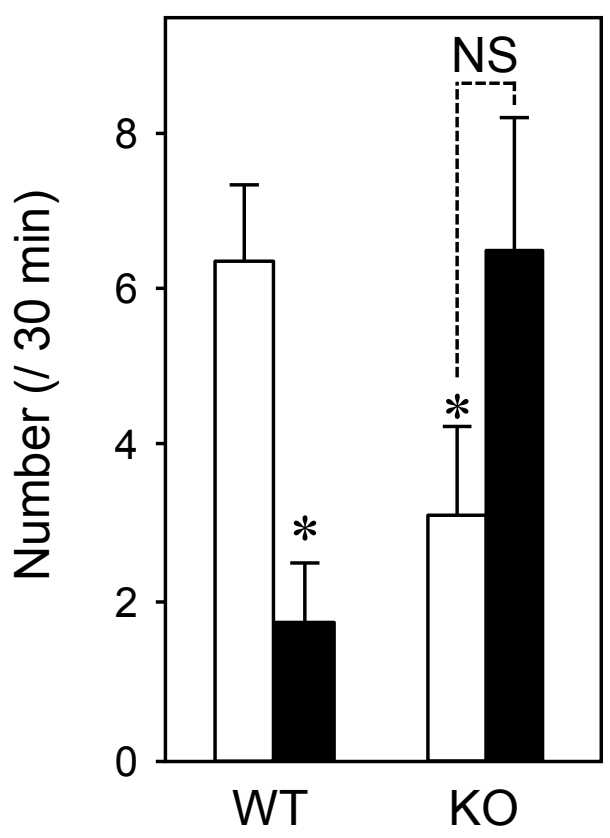

Latency

(10-11 week-old)

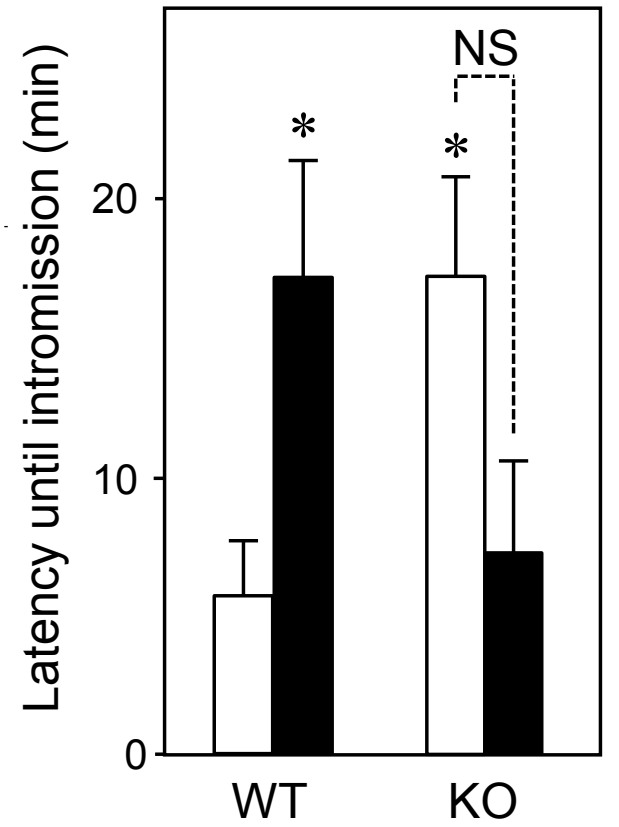

$\square$ Control 
Hattori et al., Fig. 6

A locomotor B anxiety-related behavior activity

(5 week-old)

(5 week-old)
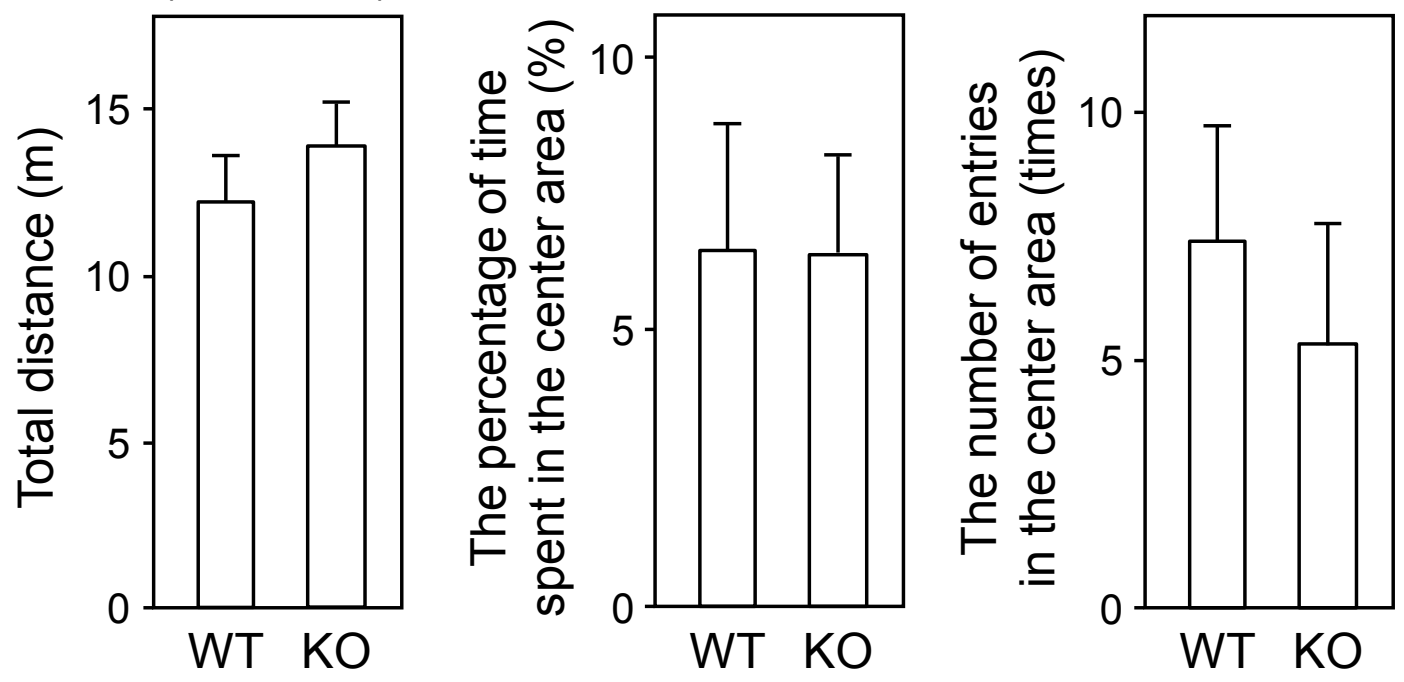
Hattori et al., Fig. 7

A LH $\beta$ mRNA

(GD20)

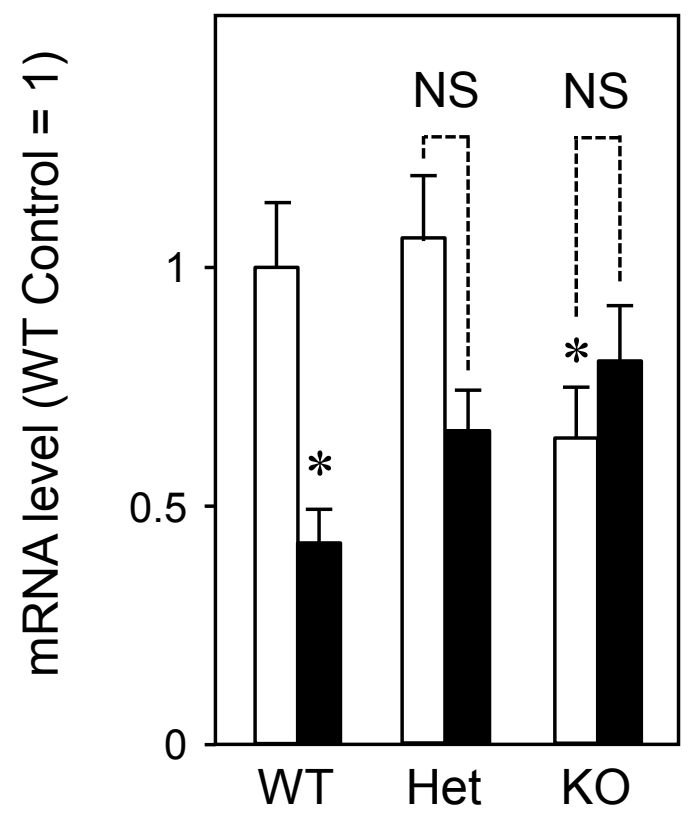

FSH $\beta$ mRNA

(GD20)

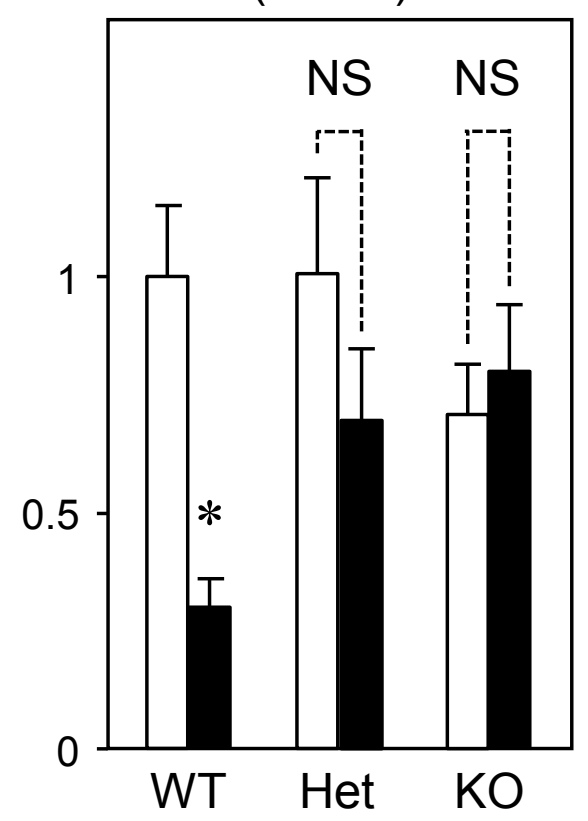

B Saccharin preference

(9 week-old)

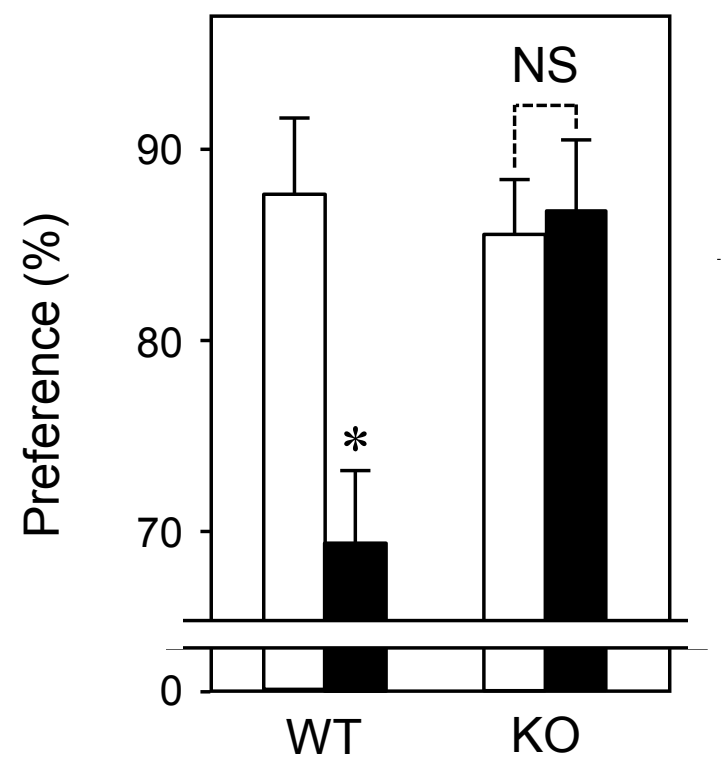

$\square$ Control

口 TCDD 


\section{Graphical Abstract}

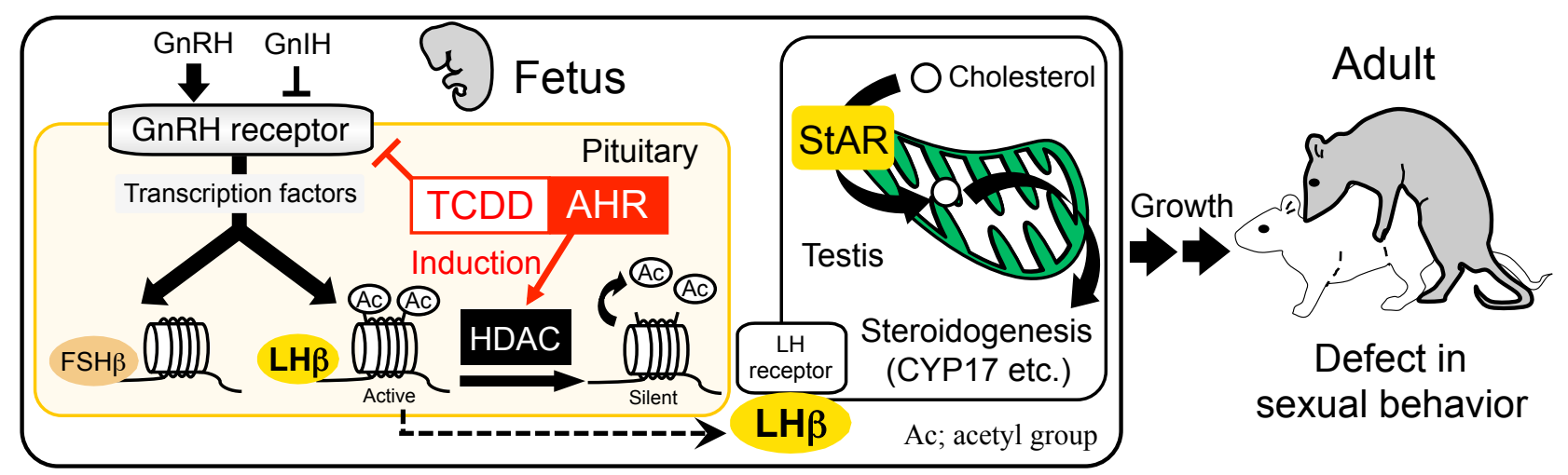

